\title{
EEN DUITSCH MEDICUS IN ESSEQUEBO IN DE LAATSTE JAREN DER 18e EEUW
}

DOOR

\section{K. KESLER}

Essequebo, in de oudste stukken genoemd Isekepe, was met Pomeroon een der eerste vestigingen van Zeeuwen op de kust van Zuid-Amerika. Sedert 1632 hadden de beide koloniën onder het beheer van de Kamer van Zeeland der West-Indische Compagnie gestaan, die echter van geen van beide veel voordeel gehad had. In het laatst der 18e eeuw was Pomeroon vrijwel verlaten en Essequebo geheel overvleugeld door de, tijdens het bestuur van den Directeur L. Storm van 's-Gravesande, in 1745 gegrondveste kolonie Demerary.

In het laatste jaar van het bestaan der West-Indische Compagnie, n.l. in 179n, vestigde zich in Essequebo een Duitsch medicus, Dr. Ernst Karl Rodschied. Hij was aan de Universiteit te Marburg gepromoveerd tot „Beider Heilungswissenschaften Doktor" en had blijkbaar een groote vereering voor zijn leermeesters, aan wie hij een boekje ${ }^{1}$ ), dat hij over zijn ervaringen in Essequebo schreef eerbiedig opdroeg.

Vóór zijn vertrek had hij den toenmaligen Rector Magnificus der Universiteit, den Geheimrat Baldinger, beloofd, van tijd tot tijd iets omtrent zijn ondervindingen in Zuid-Amerika te melden. Die belofte kwam hij na en Baldinger vond zijn eersten brief zoo belangwekkend, dat

1) Medizinische und Chirurgische Bemerkungen über das Klima, die Lebensweise und Krankheiten der Einwohner der Holländischen Kolonie Rio Essequebo, von Ernst Karl Rodschied, Beider Heilungswissenschaften Doktor. Frankfurt 1796.

West Indische Gids XI 
hij dezen in extenso liet afdrukken in een, door hem geredigeerd, vakblad, het „Physisch-Medizinische Journal". Deze bijval, dien een brief, steunende op een ervaring van slechts ongeveer een halfjaar, vond, was voor Rodschied aanleiding, eenige jaren later het voornaamste uit zijn geregeld bijgehouden dagboek te publiceeren. Het boekje, vooral de voorrede. doet hem kennen, als een ernstig, menschlievend medicus, die ten zeerste begaan was met het lot der slaven, al moet hierbij meteen vermeld worden, dat hij in zijn beschouwingen daaromtrent nog niet ver boven zijn tijd staat, minder althans, dan in andere opzichten. Dat blijkt o.a., wanneer hij den toestand der negers bespreekt. In zijn boekje wijdt hij de noodige aandacht aan den invloed, dien het klimaat op de kolonisten heeft, een invloed, dien hij in sommige opzichten niet gunstig acht. Bij slaven echter, aldus Rodschied, is deze geen factor van beteekenis, want deze zijn naar Essequebo over gebracht uit een vrijwel gelijksoortig klimaat in Afrika; hun levensomstandigheden zijn niet beduidend veranderd en slechts enkelen hunner gevoelen het vernederende van den slaventoestand. Dat zijn degenen, die in hun eigen land vrij waren en als gevangenen verkocht werden. Bij deze categorie komt het wel voor, dat zij uit wanhoop zelfmoord plegen. De meesten echter zouden in hun vaderland toch ook slaaf geweest zijn. Vlijtige, gewillige negers hebben het in Essequebo dan ook zoo kwaad niet. Enkelen hebben het ongeluk in handen van slechte en gierige meesters te vallen, maar over het algemeen is het lot der negerslaven in onze koloniën vrij wat beter, dan dat van hun lotgenooten in Oostersche landen, beter zelfs, dan dat van vele vrije arbeiders destijds in Europa. Dit laatste licht de schrijver toe, door erop te wijzen, dat in den regel in Essequebo de werktijd der slaven niet overmatig lang was. Gewoonlijk werkten zij van 's-morgens half zes tot 8 uur; daarna van 9-12 en van 1--6 n.m., dus in het geheel $10 \frac{1}{2}$ uur per etmaal. De dagtaak werd onderbroken door geregelde rusttijden van 8-9 en van 12-1. De Zondagen waren geregeld vrij en alleen in bijzondere omstandigheden, b.v. 
gedurende den oogsttijd, of, als er nieuwe gebouwen moesten worden opgezet, werd langer werken van de slaven geëischt.

Over kleeding, voeding en huisvesting der slaven is Rodschied minder goed te spreken. Uit zijn mededeelingen daaromtrent blijkt, dat hierbij veel minder op de belangen der slaven gelet werd, dan b.v. in Suriname volgens de bepalingen van het slavenreglement van 1851 het geval was. In Essequebo was tijdens Rodschieds verblijf veel aan de welwillendheid en het oordeel van de meesters overgelaten, te veel volgens onzen medicus. Een verstandige plantage-eigenaar, zoo zegt hij, zorgt in zijn eigen belang ervoor, zijn slaven voldoende te voeden, te kleeden en te huisvesten, maar er zijn maar al te veel onwelwillende en gierige meesters, die hun het noodige onthouden.

Gewoonte is het, dat eens per jaar uitdeeling van kleeding gehouden wordt, bestaande voor een man uit een lap katoen van $3 \times 3 \frac{3}{4}$ el, linnen voor een hemd, een kamizool van grof laken en een hoed. Vrouwen krijgen wat meer linnen en katoen, maar geen kamizool en geen hoed. Bovendien krijgen de slaven en slavinnen bij aankomst op de plantage gewoonlijk ieder een kookpot, een mes, naalden en garen en soms een spiegeltje. De mannen krijgen dan bovendien een scheermes. Er zijn echter genoeg plantage-eigenaars, die zich met die jaarlijksche uitdeelingen niet ophouden.

Dat een medicus en hygiënist, zooals Rodschied blijkens zijn geschrift ook geweest is, op verschillende, volgens hem veel erger, misstanden in de behandeling der slaven de aandacht vestigt en middelen tot verbetering voorslaat, spreekt vanzelf. Wat de hygiëne aangaat, vond hij vrijwel alles beneden peil. Niet alleen de toestand, waarin de slaven verkeerden, maar ook niet minder allerlei, wat de blanke betrof. Verschillende opmerkingen doen hier vooral zien, dat Rodschied in vele opzichten zijn tijd vooruit was. Hij acht het een vooroordeel, dat het klimaat ongezond zou zijn; een vooroordeel, dat de Europeaan vóór 4 uur 's-namiddags zijn huis niet moest verlaten en 
eveneens een vooroordeel, dat men in de maneschijn niet met onbedekt hoofd moet loopen. Dat het land een reputatie van ongezondheid gekregen heeft, schrijft hij, is uitsluitend toe te schrijven aan de ongebonden levenswijze der kolonisten, al geeft hij toe, dat daarin geleidelijk eenige verbetering bij vroeger gekomen is. In de tijden der eerste vestiging was Essequebo ongetwijfeld ongezond; dagelijks moesten de menschen in den moerassigen bodem arbeiden en om zich tegen de kwade dampen des nachts te beschermen was het een vaste gewoonte zich 's-avonds een stevigen roes in te drinken. Dat was in Rodschieds tijd zeer verbeterd; het land was beter gedraineerd en in sommige opzichten waren de levensgewoonten der betere klassen wat minder ruw geworden.

Maar toch, al werd de jeneverflesch ook niet meer den geheelen dag aangesproken, zooals in de eerste tijden der vestiging het geval geweest was, rijkelijk veel werd er wel gedronken. In den loop der jaren hadden zich in Essequebo verschillende Engelschen, afkomstig van de Antillen gevestigd ${ }^{1}$ ) Die hadden den smaak voor rum medegebracht en tijdens Rodschieds verblijf werd die drank bij alle gelegenheden, te pas of te onpas genoten. Alles werd met rum vermengd. Koffie dronk men ook wel, maar op Hollandsche wijze, zegt de schrijver, zeer slap en thee juist zoo sterk, dat tusschen koffie en thee geen verschil te zien was. In beide kwam een goede scheut rum; koffie met rum noemde men koffie-cordial. Met rum maakte men allerlei andere mengsels. Met eieren, melk en suiker geklopt noemde men den drank bob, met limoensap, suiker en water koude punch, met suikerrietsap en citroenschillen black syrup; bier met rum heette diversion en wijn met rum kill-man.

Het is waarlijk niet te verwonderen, dat een verstandig

1) Vooral tijdens het bestuur van Storm van 's-Gravesande waren vele Engelschen van Antigua en Barbados, wien het daar minder goed ging wegens de onvruchtbaarheid van den bodem en de hooge lasten, die zij te betalen hadden, naar Eeesquebo en Demerary geëmigreerd. Storm van 's-Gravesande bevorderde hun vestiging zooveel mogelijk en wist in 1743 te bewerken, dat nieuw-aangekomenen 10 jaar vrijstelling van hoofden recognitiegelden kregen. 
medicus, als Rodschied blijkbaar was, op die drinkgewoonten eenige malen in zijn geschrift terugkomt. Hij geeft toe, dat er een verklaring, zij het ook geen verontschuldiging voor te vinden was, n.l. het ontbreken van goed drinkwater. Dat was ook, en vooral, een nadeel voor de slaven-bevolking. Daarom wijst hij er herhaalde malen op, dat het niet alleen uit een oogpunt van humaniteit, maar ook in het wel begrepen eigenbelang der planters noodig was, te zorgen, dat de slaven goed drinkwater kunnen krijgen en niet genoodzaakt moesten worden, hun toevlucht te nemen tot het brakke rivierwater of het onzuivere zwampwater. Hij beschrijft zelfs een eenvoudig filtreertoestel, zooals hij dat aan boord der schepen gezien had. Blijkbaar echter had hij in dit opzicht weinig invloed, althans hij zegt, dat men er niet spoedig toe komt, iemand water te geven, om zijn dorst te lessen, eer wijn. Vele van de heerschende ziekten schrijft hij dan ook niet toe aan het klimaat, maar o.a. aan het gebrek aan goed drinkwater ${ }^{\mathbf{1}}$ ).

Rodschied wijdt natuurlijk ook zijn aandacht aan voeding en woningen. Op beide vond hij heel wat aan te merken en het is wel opmerkelijk, dat vele zijner aanwijzingen, meer dan een eeuw geleden gegeven, en nog wel in een tijd, toen men, althans in de West, van hygiëne nog niet veel verstand had, nog thans vrijwel onveranderd hun waarde hebben. Vleesch wordt te veel gegeten, een verkeerde gewoonte, die de oudste kolonisten medebrachten en die door de komst der Engelschen niet weing verergerde. De eerste planters waren vaak gewezen zeelieden, leefden echt „matrosenartig" en dronken van den vroegen morgen tot den middag jenever. Dan werd de maaltijd gebruikt, waarbij gezouten vleesch, spek, haring, stokvisch, gort e.d. op tafel kwamen en waarbij een goede hoeveelheid roode wijn gedronken werd. Later verscheen dan weer de jeneverflesch, vooral als voorbehoedmiddel tegen de

1) Welche grausame Verwüstungen dieser Wassermangel anrichten muss, wie empfänglich in diesen Jahreszeiten (den drogen tijd) der Körper für faulichte Epidemiën seyn muss, ist jedem verständigen hund gelehrten Arzt einleuchtend. 
kwade dampen van den avond en tegen de muskietenbeten. Plantaardig voedsel gebruikt men veel te weinig, vooral te weinig groenten. Bananen, die veel gegeten worden, omdat meel aangevoerd moet worden en dus duur is, vormen een goed voedse! voor hen, die zwaren arbeid moeten verrichten, maar zij zijn moeilijk verteerbaar en daarom minder geschikt voor zwakke personen en voor hen, die een zittend leven moeten leiden. Rodschied betreurt het zeer, dat spaarzaamheid en gierigheid en vooral de begeerte, zoo spoedig mogelijk rijk te worden de menschen in Essequebo ertoe brengt, te weinig aandacht aan zulke dingen, als juiste voeding te wijden. Wat geeft het, zoo zegt hij, of men nu al rijk wordt en geen goede gezondheid bezit, die in staat stelt, van den verworven rijkdom te genieten?

Het eigenlijke medische gedeelte beslaat uit den aard der zaak een belangrijke ruimte in het boekje en zelfs den leek, die van de behandeling van ziektegevallen geen verstand heeft, moet 't hierin opvallen, dat de schrijver, naar de mode van zijn tijd, een groote voorliefde voor het aderlaten blijkt te hebben. Voor den medischen dienst in Essequebo heeft hij allerminst bewondering en evenmin voor de meesten van zijn collega's. Hij drukt er zijn verwondering over uit, dat er geen enkele wettelijke regeling van dien dienst is, althans hij heeft van het bestaan daarvan nooit iets gemerkt. Het gevolg daarvan en van de omstandigheid, dat van geneeskundigen geen enkel bewijs van bekwaamheid wordt gevorderd, is, dat iedereen dokter kan worden. Daarvoor is het genoeg, dat hij zichzelf bekwaam verklaart en velen beginnen aan hun eigen kundigheden te gelooven, zoodra zij een beetje gekwakzalverd hebben met rhabarber of jalappe. Onder zijn collega's telde hij er, die vroeger apothekersleerling, barbier of zelfs hoefsmid geweest waren. Sommigen hunner en dat waren de minst onbekwame, hadden een opleiding van twee jaar achter den rug. Het eerste jaar hadden zij de apotheek moeten schoonmaken, kolen moeten aandragen en medicijnen bij de patiënten bezorgen en ook weleens poeders moeten stampen. Begane fouten werden 
door den meester met een pak slaag gecorrigeerd. Het tweede jaar mochten zij dan zelfstandig geneesmiddelen klaar maken, waarbij de meesten gebruik maakten van één enkel boek: Buchan's Domestic medicine. Voor andere boeken hadden die zoogenaamde dokters een heilige vrees en met studie hielden zij zich bij voorkeur niet op. „Wie niet gelooven wil," zegt Rodschied," dat de dokterstitel niet voor onwetenheid beschermt, die kome naar Essequebo en hij zal overtuigd worden." Het is begrijpelijk, dat iemand, als de schrijver, die een wetenschappelijke opleiding genoten had en die blijkbaar het einde van zijn universiteitsjaren nog niet als het einde van zijn studie beschouwde, wel eens den spot drijft met zijn "geleerde" collega's. Bij de beschrijving der planten die hij o.a., met het oog op zijn practijk in Essequebo bestudeerd had, vermeldt hij o.a. Crinum Americanum, een plant, die tot de Amaryllisachtigen behoort en die o.a. op onze Bovenwindsche eilanden gekweekt wordt en onder den naam van Lily bekend is. Een van Rodschieds collega's was het echter met diens determineering ervan niet eens. Rodschied schrijft daarover: „Ein hiesiger Arzt erklärte einst in gelehrtem Taumel, diese Pflanze für Scilla maritima.L. Er habe sie hundertmalen in botanischen Gärten gesehen, in seinem eigenen selbst gezogen”. En ironisch voegt hij erbij: „Von diesem Augenblick war das Glück dieser Pflanze gemacht und sie zur Medizinalpflanze erhoben".

Het behoeft ons na de mededeelingen van Rodschied niet te verwonderen, dat de ko'onisten, die uit zuinigheid, om hun niet te veel te behoeven te betalen, dergelijke artsen goed genoeg voor hun slaven vonden, zich er liever zelf niet aan toevertrouwden. En Rodschied ergert zich erover, dat zij niet trachten, betere artsen te verkrijgen, maar zich vaak tot de Indiaansche piaimannen wenden. Hij zegt daaromtrent ongeveer: Dat de Indiaan naar zijn piaiman gaat, is even natuurlijk, als dat de Europeaan den heer dokter met zijn groote pruik laat roepen. Maar, als de Europeaan zich een kreek laat oproeien, om een piaiman te raadplegen getuigt dat van een ziekte 
in zijn hersenen, die alleen door een schedeloperatie kan worden genezen.

De uitgave van een werkje, waarin allerlei misstanden aan de kaak gesteld werden, al was ook de eenige bedoeling van den schrijver te trachten er verbetering in te brengen, wekte natuurlijk de verontwaardiging van velen in Essequebo. En blijkbaar lieten dezen niet na, ter verdediging van geheime tegenwerking en laster gebruik te maken. Een enkele maal keert de schrijver zich tegen deze tegenstanders door te verklaren: „Der brutale Stolz der Unwissende und deren geheime Künste und schleichende Versuche mir zu schaden, verachte ich zu viel, als dass ich es der Mühe werth halten sollte auch nur wenige Worte darum zu verlieren. Menschen deren ganzes Ich nur durch den Geldsack Gewicht bekommt, sind ein würdiger Gegenstand der Verachtung vernünftiger Wesen".

Rodschied heeft dus blijkbaar tegenwerking genoeg ondervonden, maar zijn bedoeling was goed. Vooral met het lot der slaven was hij op verstandige wijze en zonder overdrijving innig begaan. „Traurig ist es anzusehen”, zoo schrijft hij, „wie durch missverstandene Politik der kranke Neger oft unmenschlich behandelt wird.... ich würde mich ungemein glücklich schätzen, wenn ich hierdurch auch etwas zur Erleichterung meiner schwarzen Brüder beigetragen hätte." Vertroetelen behoeft men den „zwarten broeder" daarom niet; het is evenmin noodig, dat de neger in weelde leeft, als dat de Duitsche boer een lichtkroon in zijn huis heeft. Het is echter te vreezen, dat Rodschieds optreden niet belangrijk het lot der slaven zal hebben verbeterd. Een enkele plantagehouder zal misschien overtuigd geworden zijn, dat hij geen vee, maar zwarte menschen aan het werk had, en dat het bovendien in zijn eigen belang was, hen niet al te veel te verwaarloozen en te mishandelen. Trouwens, zoo erg, als dat in Suriname geschiedde, schijnt men het in Essequebo niet gedaan te hebben. Een der voor de hand liggende redenen daarvan was wel, dat slaven er betrekkelijk zeldzaam waren. Dit verklaart tevens, dat de kolonie eigenlijk nooit gekend heeft een tijd van 
bloei en grooten rijkdom, zooals die van Suriname in de $18 \mathrm{e}$ eeuw. Slaven werden slechts zelden direct uit Afrika aangevoerd; tusschen de jaren 1749 en ' 65 , dus gedurende 17 jaren kwamen niet meer dan vier ,armazoenen” aan. Daardoor waren de planters genoodzaakt, òf hun slaven in Suriname te gaan koopen, òf ze binnen te smokkelen, als zij ze elders konden verkrijgen. Roode slaven waren evenals in Suriname in Essequebo zeldzaam. Zooals bekend is, werden de Indianen „bokken” genoemd. Rodschied beproeft een verklaring voor die vreemde benaming te geven. Hij zegt: In het Arowaksch is mensch lockóhó, wat snel uitgesproken klinkt als lockó. Vraagt men nu een Arowak: Wie zijt gij ?, dan zal hij wellicht antwoorden: Dai lockóhó (d. i. : Ik ben een mensch). wat misschien verstaan kan worden, als bok. Misschien, inderdaad zeer misschien; het lijkt een afleiding, als die van lantaren uit lamptoren! Etymologie, evenmin als geschiedenis, behoort niet tot de sterkste gedeelten van de kennis van dezen dokter.

Wat de geschiedenis betreft, biedt zijn boekje een paar vermakelijke staaltjes aan. Hoe zijn de Hollanders ertoe gekomen, zoo vraagt hij zich af, om negers als slaven te gebruiken en slechts bij uitzondering Indianen? En in onze geschiedenis vindt hij het antwoord. De Hollanders hadden zoo lang tegen Spanje voor hun vrijheid gestreden dat zij zich erin konden verplaatsen, dat een trotsch, vrijheidlievend volk, als de Indianen, zich niet onder de slavernij kon bukken. Daarom lieten zij die met rust. Tot zoover is het bégrijpelijk, als het waar was. Maar, dat zij dáárom negers als slaven gingen invoeren, ligt minder voor de hand. Ook de voorstelling van de stichting van de kolonie Rio Essequebo, die Rodschied geeft, is eenigszins eigenaardig. In 1665 (!) zoo verhaalt hij, ruilden de Hollanders Suriname, - das jetzt so blühende Surinam mit den schönen Paramaribo, - met de Engelschen tegen New-York. Toen nu in Suriname niets meer voor de „,industriösen Holländer” te ondernemen was, gingen zij verder naar het Westen en stichtten achtereenvolgens Berbice, Demerary en Essequebo. 
Men ziet het, van de koloniale geschiedenis was de dokter niet geheel op de hoogte; trouwens dat geeft hij zelf toe, want bij zijn kort en onjuist historisch overzicht erkent hij: „Wann dieser Period der ersten Gründung dieser Kolonie gewesen ist, ist mir unbekannt". Voor Essequebo vermoedt hij, dat zij in zijn tijd ongeveer een menschenleeftijd geleden zal geweest zijn, „denn”, zoo zegt hij, „man findet sehr alte Creolen hier.” Maar reeds in het begin der 17e eeuw waren er Hollanders!

Intusschen dit daargelaten, uit het boekje krijgt men den indruk, dat Rodschied een voor zijn tijd bekwaam medicus geweest is, die zeker hoog stond boven velen zijner collega's.

Amsterdam, Mei 1929. 